\title{
Enxerto subepitelial de tecido conjuntivo e enxerto gengival livre para recobrimento radicular-relato de dois casos clínicos
}

\author{
Subepithelial connective tissue graft and free gingival graft for root recovery-report of two \\ clinical cases
}

Injerto de tejido conectivo subepitelial e injerto gingival libre para el recubrimiento radicular: informe de dos casos clínicos

\begin{abstract}
Vitória Hewelly Santiago de Lima ${ }^{1}$, Maria Joane Coelho de Sousa ${ }^{1}$, Larice Kércia Braz Monteiro Vilana Maria Adriano Araújo ${ }^{1,2}$, José Laurentino Ferreira Filho ${ }^{1,3}$, Mariana Canuto Melo de Sousa Lopes $^{1}$, Ernanda Maria de Araújo Sales ${ }^{1,2}$, Flávia Jucá Alencar e Silva ${ }^{1,2}$, Jacqueline de Santiago Nojosa $^{1,2}$, Mariana Vasconcelos Guimarães ${ }^{1,2 *}$.
\end{abstract}

\section{RESUMO}

Objetivo: Comparar manejos cirúrgicos e resultados funcionais e estéticos entre as técnicas de recobrimento radicular de Enxerto Subepitelial de Tecido Conjuntivo (ESTC) e Enxerto Gengival Livre (EGL) através de relatos de casos clínicos. Detalhamento do caso: Duas pacientes com idades de 21 anos e finalizando tratamento ortodôntico compareceram ao Complexo Odontológico São João Calábria da UNICATÓLICA, com recessão gengival (RG). Após os exames periodontais e sistêmicos, observou-se RG no dente 41 . As pacientes foram informadas sobre os riscos e os benefícios do estudo para, então, assinarem o Termo de Consentimento Livre e Esclarecido. Após anestesia, para o EGL e o ESTC, respectivamente, procedeu-se, no leito receptor, com incisão horizontal na linha mucogengival e desepitelização, ou retalho em envelope após incisão intrasulcular, com descolamento mucoso de retalho. Quanto ao leito doador, no palato duro, o tecido a ser enxertado, foi removido adequadamente, de acordo com as necessidades de cada técnica, acomodado ao leito receptor e fixado através de suturas com fio de nylon, incluindo sutura suspensória para - ESTC. Após 2 meses, na técnica do EGL, observou-se boa cicatrização e recuperação de tecido queratinizado, porém com deficiência estética dada à divergência de cor do enxerto em relação ao epitélio do leito receptor. O recobrimento radicular mais pronunciado, com melhor aparência estética, ocorreu apenas para o ESTC. Conclusão: O EGL e o ESTC apresentam resultados clínicos satisfatórios, porém diferentes entre si, quanto aos aspectos funcionais e estéticos do periodonto.

Palavras-chave: Recessão gengival, Enxerto de tecidos, Gengiva.

\begin{abstract}
Objective: To compare surgical management and functional and aesthetic outcomes between the root coverage techniques Subepithelial Connective Tissue Graft (ESTC) and Free Gingival Graft (EGL) through of case reports. Case Details: Two patients aged 21 years and finishing orthodontic treatment were attended in UNICATÓLICA São João Calabria Dental Complex, with gingival recession (RG). After periodontal and systemic examinations, RG was observed in tooth 41 . The patients were informed about the risks and benefits of the study and then signed the Informed Consent Form. After anesthesia, for EGL and ESTC, respectively, a horizontal incision in the mucogingival line and de-epithelization was performed on the recipient site, or and envelope flap after intrasulcular incision, with mucosal flap. As for the donor site, in the palate, the tissue to be grafted was properly removed, according to the needs of each technique, accommodated to the receiving site
\end{abstract}

\footnotetext{
${ }^{1}$ Centro Universitário Católica de Quixadá (UNICATÓLICA), Quixadá-CE.

*E-mail: marianav_guimaraes@yahoo.com.br

2 Universidade Federal do Ceará (UFC). Fortaleza -CE.

3 Universidade Estadual de Campinas (FOP-UNICAMP). Campinas-SP.
} 
and fixed through sutures with nylon thread, including suspension suture for the ESTC. After 2 months, in the EGL technique, good healing and recovery of keratinized tissue were observed, but with aesthetic deficiency due to graft color divergence from the epithelium of the recipient site. The most pronounced root cover, with the best aesthetic appearance, occurred only for the ESTC. Conclusion: EGL and ESTC present satisfactory clinical results, but different in terms of funcional and aesthetic aspects of the periodontium.

Keywords: Gingival recession, Tissue grafting, Gingiva.

\section{RESUMEN}

Objetivo: Comparar el manejo quirúrgico y los resultados funcionales y estéticos entre las técnicas de cobertura de raíz del injerto de tejido conectivo subepitelial (ESTC) y del injerto de encía libre (EGL) através de informes de casos. Detalles del caso: Dos pacientes de 21 años y en tratamiento de ortodoncia asistieron al Complejo Dental UNICATÓLICA São João Calabria, con recesión gingival (RG). Después de los exámenes periodontales y sistémicos, se observó RG en el diente 41. Los pacientes fueron informados sobre los riesgos y beneficios del estudio y firmaron un formulario de consentimiento informado. Después de la anestesia, para EGL y ESTC, respectivamente, se realizó una incisión horizontal en la línea mucogingival y epitelización en el sitio receptor o colgajo de la envoltura después de la incisión intraesulcular con colgajo mucoso. Con respecto al sitio donante, en el paladar, el tejido a injertar se eliminó adecuadamente, de acuerdo con las necesidades de cada técnica, se acomodó en el sitio receptor y se fijó a través de suturas de nylon, incluida la sutura de suspensión para el ESTC. Después de 2 meses, la técnica EGL mostró una buena curación y recuperación del tejido queratinizado, pero con deficiencia estética debido a la divergencia del color del injerto epitelial del sitio del receptor. La cobertura de raíz más pronunciada con la mejor apariencia estética se produjo solo para ESTC. Conclusión: EGL y ESTC presentan resultados clínicos satisfactorios, pero diferentes en términos de aspectos funcionales y estéticos del periodonto.

Palabras clave: Recesión gingival, Injerto de tejido, Gengiva.

\section{INTRODUÇÃO}

A Retração Gengival (RG) relaciona-se a exposição da raiz e Junção Cemento-Esmalte (JCE) após uma migração apical da margem da gengiva (HYTHAM N, et al., 2019; CORTELLINI P e BISSADA N, 2018). Tal acometimento mucogengival oriunda de vários fatores, como mal posicionamento dos dentes, alta fixação frenal, trauma relacionado à escovação, inflamação associada à presença de biofilme ou cálculo, fatores como próteses e restaurações inadequadas e especialmente, histórico de tratamento ortodôntico, sobretudo em pacientes com fenótipo periodontal fino (KANUT A, et al., 2019).

Estes, por sua vez, são mais susceptíveis às sequelas consequentes do rearranjo estrutural ósseo e dentário durante tratamento ortodôntico, como deiscência do osso alveolar, ou melhor, perda óssea associada à deficiência no volume de tecido mole e insuficiente tecido queratinizado (WANG G, et al., 2019; EDYTA K, et al., 2019; CORTELLINI P e BISSADA N, 2018; JEPSEN S, et al., 2017).

Problemas funcionais e estéticos secundários à RG podem estar relacionados, respectivamente, à perda da proteção oferecida pela consistência firme característica de tecido gengival queratinizado ou às alterações no contorno gengival. Desta forma, alternativas associadas a métodos cirúrgicos periodontais foram desenvolvidas no intuito de recobrir a área desnuda oriunda da RG (JENABIAN N, et al., 2016).

Dentre estas, destacam-se técnicas envolvendo o enxerto de tecido autógeno, como o retalho posicionado coronariamente ou lateralmente, bem como o Enxerto Gengival Livre (EGL) e o Enxerto de Tecido Conjuntivo Subepitelial (ETCS) (SEGUNDO TK e ALVES R, 2005). A saber, EGL e ETCS são técnicas preconizadas em casos específicos, como a necessidade de um tecido doador à distância da área receptora (JENABIAN N, et al., 2016).

O recobrimento radicular visa, de fato, aumentar a quantidade de gengiva queratinizada, tendo, como consequência benéfica, a diminuição da sensibilidade da raiz e a recuperação das funções do periodonto de proteção, além de melhorar os aspectos do contorno da gengiva (LUTHRA S, et al., 2018). Porém do ponto de vista funcional e/ou estético, EGL e ETCS podem se diferenciar quanto à intensidade de obtenção de seus resultados (HYTHAM N, et al., 2019). 
Assim, o presente trabalho tem como objetivo comparar as duas técnicas cirúrgicas de recobrimento radicular EGL e ETCS quanto ao manejo cirúrgico, resultados funcionais e estéticos, através do relato de dois casos similares de RG, possivelmente associada a histórico de tratamento ortodôntico em pacientes com biotipo periodontal fino.

\section{DETALHAMENTO DO CASO}

Pacientes C. R. G. e J. S. T, ambas do sexo feminino e 21 anos de idade, compareceram à Clínica do Complexo Odontológico São João da Calábria, do Centro Universitário Católica de Quixadá, Ceará, Brasil, queixando-se de sensibilidade dentária associada à $R G$ no dente 41 , relatando que a mesma lhes apareceu após o uso de aparelho ortodôntico.

Após anamnese, em que as pacientes não relataram doenças sistêmicas ou hábitos deletérios, e ao exame intraoral, onde se constatou saúde periodontal, foi diagnosticado que ambas as pacientes possuíam o biotipo periodontal fino e a referida recessão gengival classe II (Figura 1 A e B) (MILLER PD, 1985). Foram, também, realizados exames clínicos e radiográficos (Figura $1 \mathrm{C}$ e D).

Figura 1 - Aspectos clínicos e radiográficos iniciais

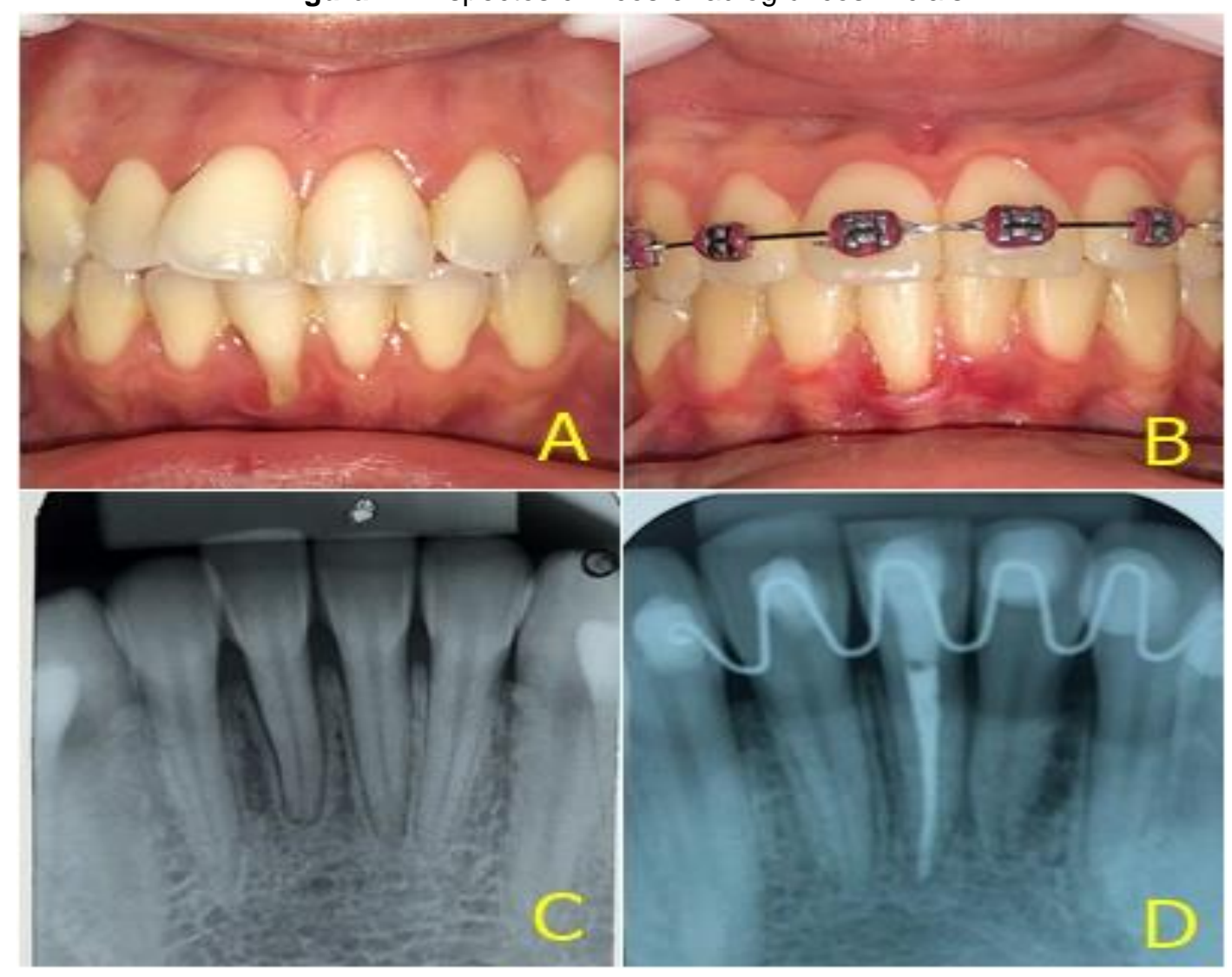

Legenda: 1A, 1B: Foto Aspecto inicial das pacientes C.R.G. e J.S.T, respectivamente; 1C e 1D: Radiografias periapicais das pacientes C.R.G. e J.S.T, respectivamente. Fonte: Lima VHS, et al., 2020.

Observa-se recessão classe II relacionadas à unidade dentária 41 em ambos os casos (MILLER PD, 1985). Nota-se, ainda, ausência de tecido doador nas proximidades da área receptora, indicando a necessidade de obtenção deste tecido à distância

O EGL e o ETCS foram as técnicas cirúrgicas preconizadas em decorrência da quantidade insuficiente de gengiva queratinizada nas proximidades do leito receptor. As pacientes foram esclarecidas sobre os riscos e benefícios dos tratamentos cirúrgicos que Ihe foram propostos e assinaram o Termo de Consentimento Livre 
e Esclarecido. Tal estudo obteve a aprovação no Comitê de Ética em Pesquisa da UNICATÓLICA, sob número de protocolo 3.600 .688

\section{RELATO DE CASO 1}

Após aferição de sinais vitais e desinfecção com iodo do campo cirúrgico, ocorreram a administração do anestésico local (lidocaína $2 \%$ com adrenalina 1:100.000), a incisão horizontal no fundo de sulco, correspondente à junção mucogengival, desepitelização da área para maior suprimento sanguíneo, preparando-a para receber o tecido a ser enxertado.

Nesta área, preservou-se, ao máximo, o tecido gengival mínimo presente, sendo este pressionado delicadamente para coronal (Figura 2 A). Com o auxílio de uma sonda milimetrada, as dimensões da área a ser coberta foram obtidas para definir o tamanho exato do enxerto (comprimento e largura) (Figura 2 B, C), utilizando-se uma guia com papel estéril, a qual foi levada à área doadora (Figura 2 D).

Figura 2 - Preparo do leito receptor e adaptação de guia no leito doador na técnica de EGL.

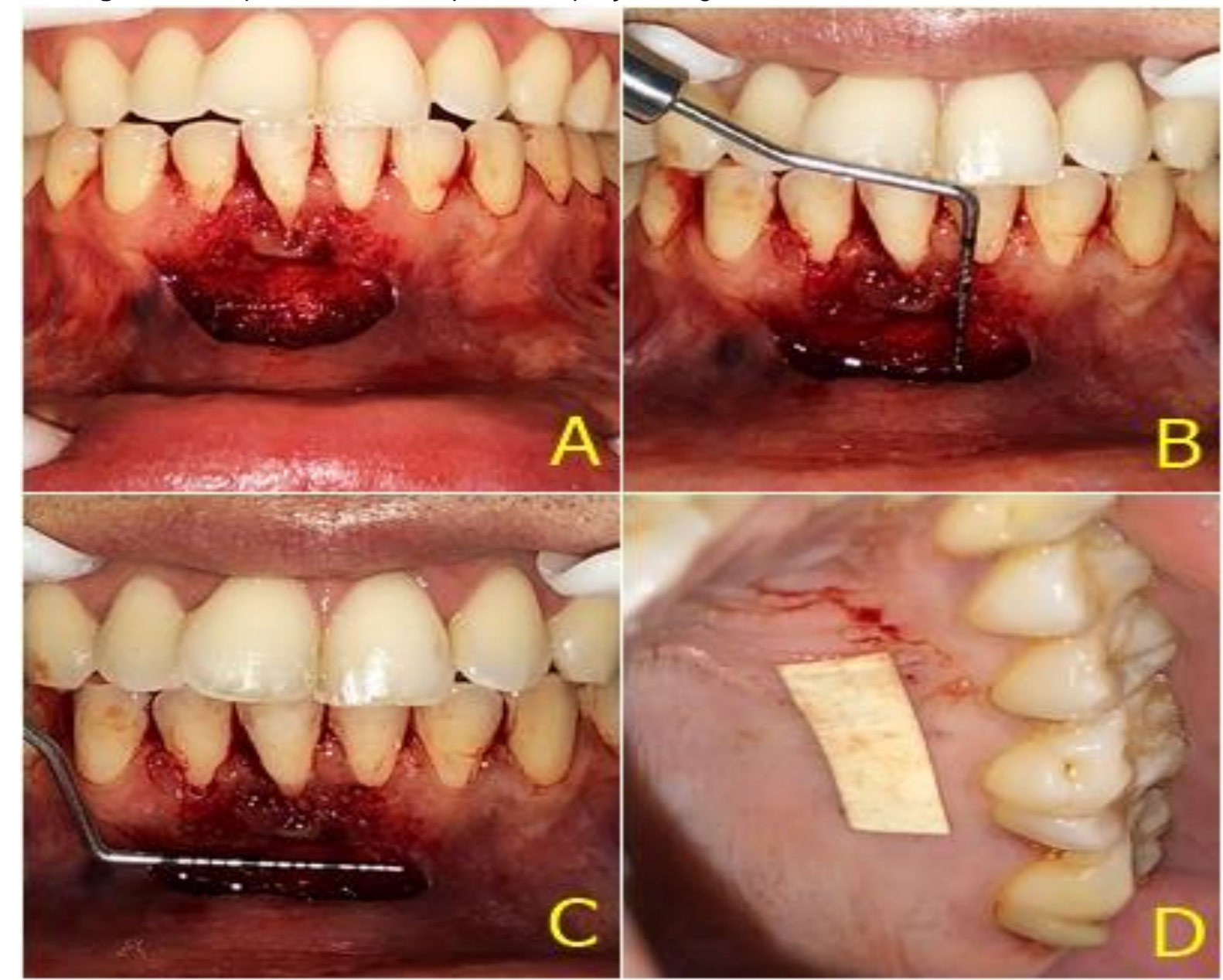

Legenda: 2A: Foto do Leito Receptor, após incisão horizontal; 2B e 2C: Dimensões do leito receptor; 2D: Guia de papel para facilitar a retirada milimetricamente necessária de tecido no leito doador.

Fonte: Lima VHS, et al., 2020.

Após anestesia e remoção cuidadosa do tecido epitelial e conjuntivo correspondente à guia no palato duro, especificamente nas regiões de primeiro pré-molar superior à distal do primeiro molar superior (Figura $3 \mathbf{A}$ ), o tecido foi banhado rapidamente em soro fisiológico (Figura 3 B) e adaptado ao leito receptor, sendo fixado ao mesmo através de suturas simples com o fio de nylon 4.0 (Figura $3 \mathbf{C}$ ). 
Figura 3 - Remoção de enxerto no palato duro para a técnica de EGL.

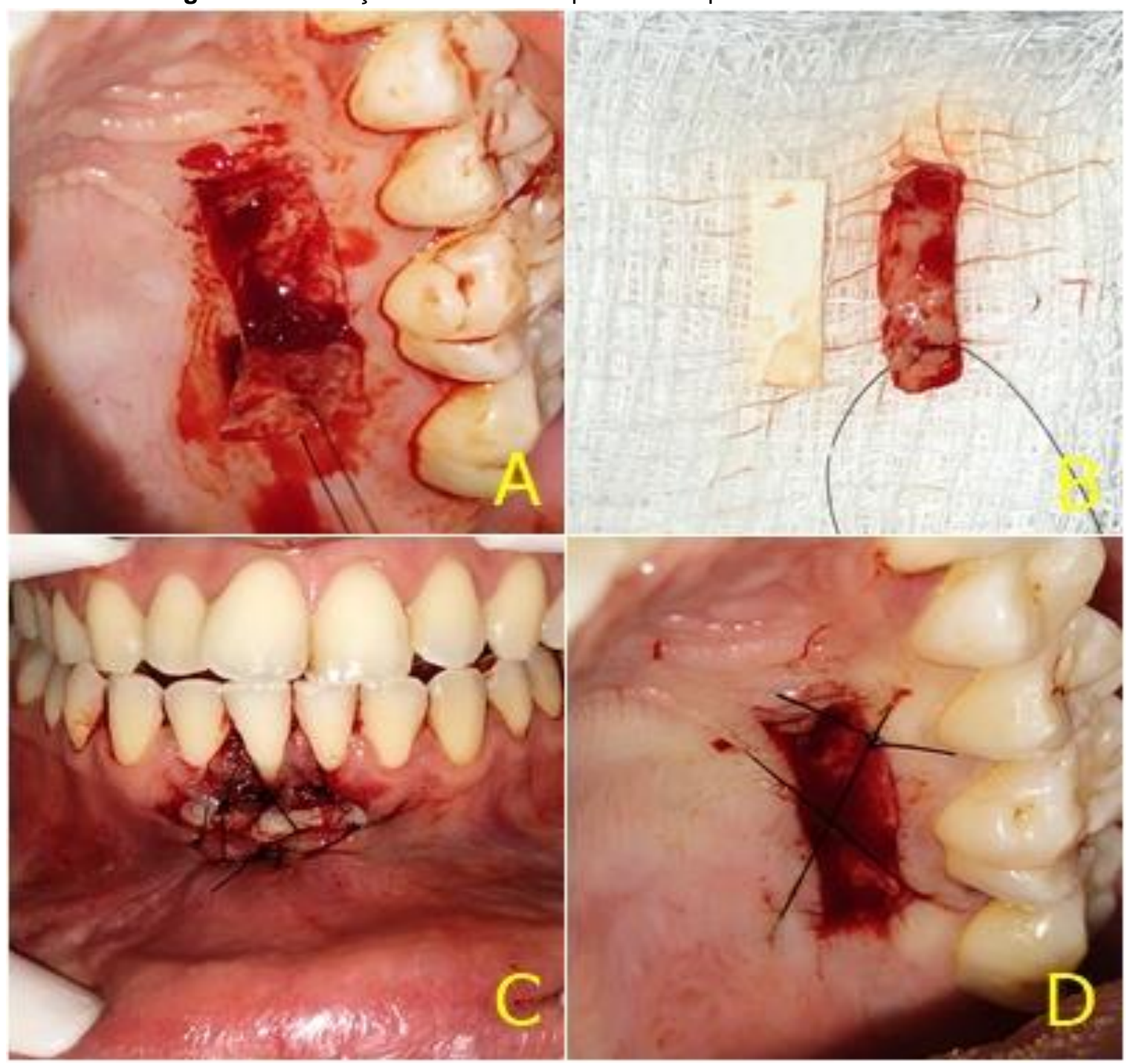

Legenda: 3A: Foto Remoção do EGL; 3B: Comparação do EGL com a guia de papel; 3C: Suturas no leito receptor; 3D: Sutura em $X$ no leito doador.

Fonte: Lima VHS, et al., 2020.

A saber, em decorrência da extensão vertical elevada da referida recessão gengival, a posição ideal do enxerto ficou limitada, não recobrindo toda a raiz, visando evitar necrose por ausência de suprimento sanguíneo. Logo, não se esperava um recobrimento tecidual completo, porém, sim, o ganho de gengiva queratinizada.

A paciente, por sua vez, foi esclarecida anteriormente ao momento cirúrgico da necessidade de uma segunda cirurgia para recobrimento radicular completo. Ao fim, a área doadora do palato recebeu seus devidos cuidados, com sutura em $X$ visando manutenção de coágulo para cicatrização por segunda intenção (Figura 3 D).

Foram prescritos analgésicos pós-operatórios (dipirona $500 \mathrm{mg}$ ) e os devidos cuidados. Após 14 dias, a paciente retornou para retirada dos pontos e avaliação da cicatrização, a qual se mostrou satisfatória.

Em 45 dias seguidos do procedimento cirúrgico, notou-se ganho considerável de gengiva queratinizada, porém, conforme mencionamos anteriormente, não foi atingido o recobrimento radicular completo. Porém, a principal desvantagem observada com relação à estética foi, ainda, a diferença de cor entre o epitélio do tecido obtido da área doadora e da região receptora (Figura 4). 
Figura 4 - Aspecto Final após 45 dias da cirurgia de EGL.

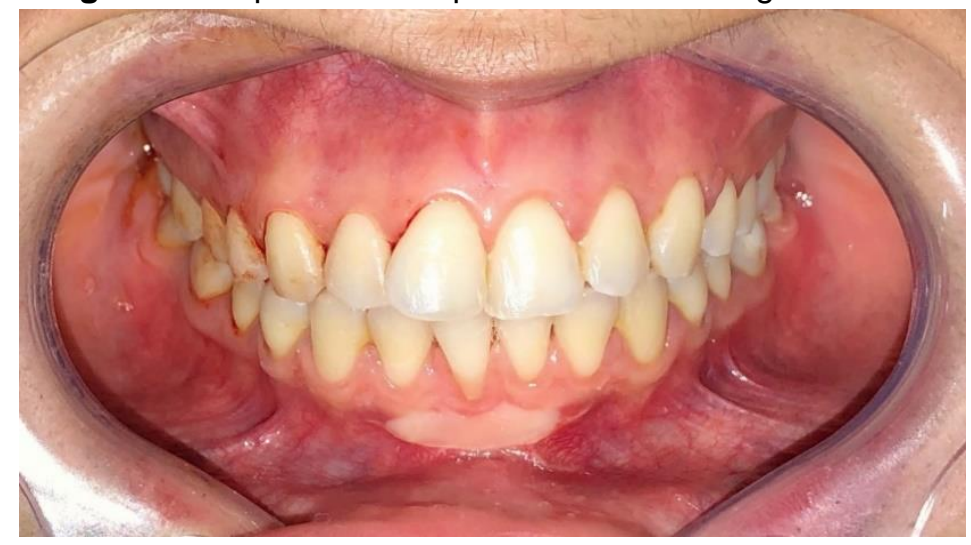

Fonte: Lima VHS, et al., 2020.

A paciente relatou desconforto apenas no primeiro dia do pós-operatório e se mostrou bastante satisfeita com tal resultado inicial, especialmente quanto à facilidade de higienização oral na região.

\section{RELATO DE CASO 2}

Após aferição de sinais vitais e desinfecção com iodo do campo cirúrgico, ocorreram a administração do anestésico local (lidocaína 2\% com adrenalina 1:100.000) e incisão horizontal na base das papilas com lâmina de bisturi 15c. Em seguida, procedeu-se com descolamento parcial de retalho a partir da linha de incisão e confecção de um retalho em envelope. As papilas, por sua vez, foram desepitelizadas (Figura 5 A). Após anestesia e remoção de enxerto (Figura 5 B), o qual consistiu essencialmente de tecido conjuntivo do palato duro, este foi inserido no interior do retalho na área receptora (Figura $5 \mathbf{C}$ ), procedendo-se, com suturas simples e suspensória do retalho em envelope, visando fixar o retalho em uma posição mais coronal que àquele habitual e cobrir o enxerto (Figura $5 \mathrm{D}$ ).

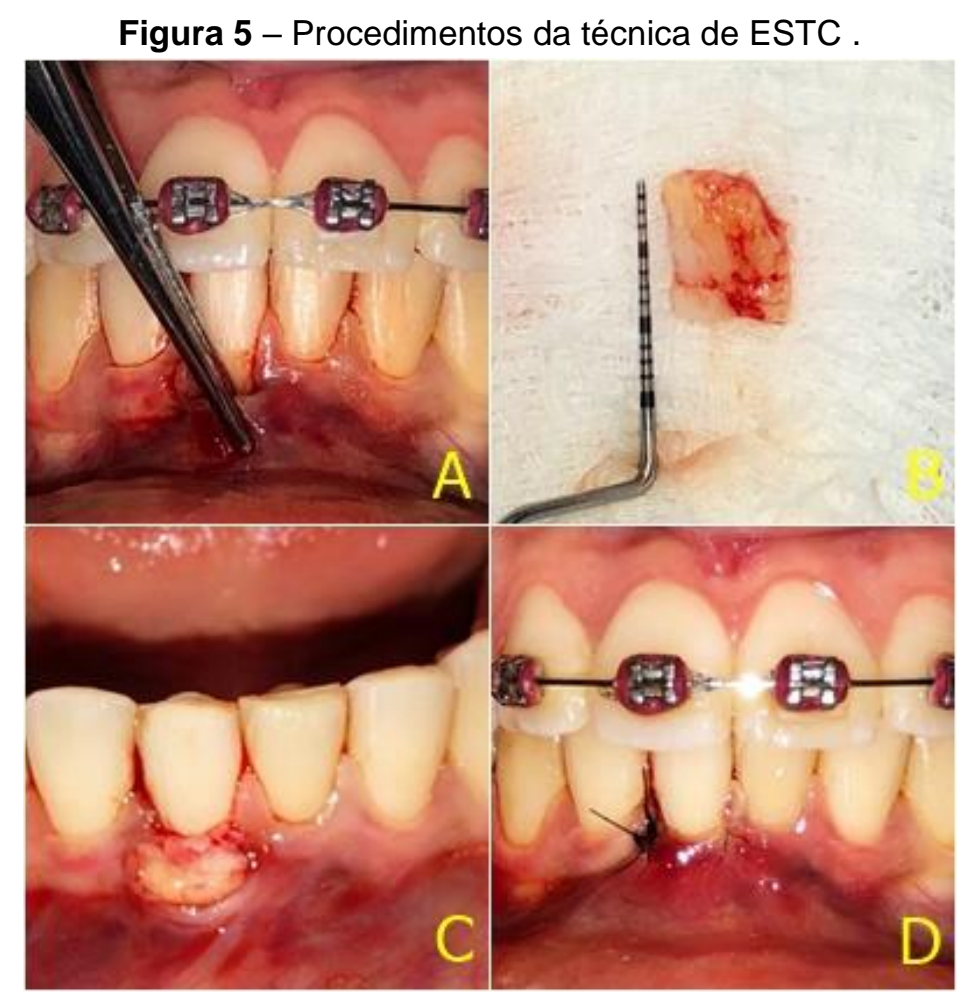

Legenda: 5A: Retalho no leito receptor em envelope; 5B: Enxerto de Tecido Subepitelial; 5C: Intrusão do Enxerto no leito Receptor; 5D: Sutura Simples. Fonte: Lima VHS, et al., 2020. 
Ao fim, a área doadora do palato recebeu seus devidos cuidados, com sutura interrompida simples. Comparativamente à técnica envolvendo EGL, notou-se uma menor exposição de tecido conjuntivo no leito doador e, consequentemente, cicatrização mais favorável do mesmo.

Foram prescritos analgésicos pós-operatórios (dipirona $500 \mathrm{mg}$ ) e os devidos cuidados. Após 14 dias, a mesma retornou para retirada dos pontos e avaliação da cicatrização, a qual se mostrou satisfatória. Em 45 dias seguidos do procedimento cirúrgico, notou-se recobrimento radicular considerável, porém com menor quantidade de tecido queratinizado de proteção comparativamente à técnica de $E G L$, sendo esta a principal desvantagem observada (Figura 6).

Figura 6 - Aspecto final do ESTC após 45 dias.

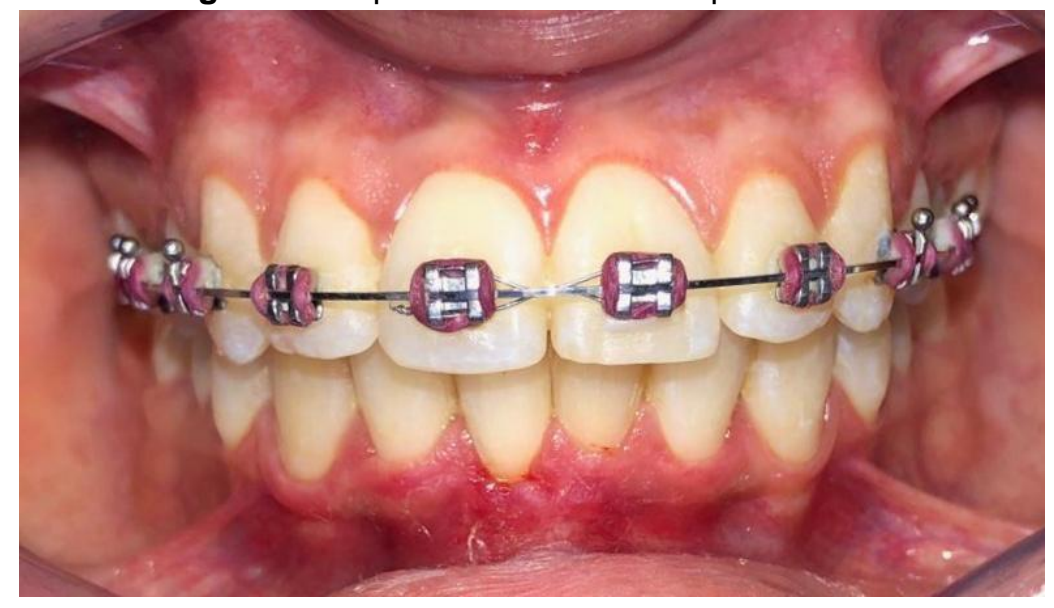

Fonte: Lima VHS, et al., 2020.

A paciente relatou desconforto apenas no primeiro dia do pós-operatório e se mostrou bastante satisfeita com tal resultado inicial, especialmente quanto à estética.

\section{DISCUSSÃO}

A RG está relacionada com a exposição da raiz e JCE após uma migração apical da margem da gengiva, de etiologia multifatorial e com maior frequência em pacientes apresentando fenótipo periodontal fino (PAWAR B, et al., 2011; JHA N, et al., 2017). Consequentemente, conforme bem salientado por inúmeros autores Com a retração gengival ocorre a perda do zênite e, em alguns casos, a perda das ameias interproximais que resultam em black space, podendo ser este um fator inestético que pode influenciar negativamente no bem estar do paciente (PATIL V e DESAI M, 2013; LOBO M, et al., 2014; GANJI KK, et al., 2018; KOLTE P, et al., 2018). Além disso, a perda de tecido queratinizado pode ocasionar em sensibilidade exacerbada na região, interferindo com hábitos diários, como a mastigação e a higienização.

Tal problema mucogengival pode ocorrer derivado de vários fatores como, por exemplo, alta fixação frenal, escovação vigorosa e tratamentos ortodônticos, os quais podem precipitar a ocorrência de fenestração e deiscência óssea (JATI AS, FURQUIM LZ E CONSOLARO A, 2016; STEFFENS J e MARCANTONIO R, 2018; GUTTIGANUR N, et al., 2018).

Dependendo do grau de acometimento interproximal e da proximidade à junção mucogengival, que em muitos casos define a quantidade de tecido perdida, as RGs podem ser classificadas em quatro graus, havendo perda de tecido interproximal a partir do grau 3 e acometimento do limite mucogengival a partir do grau 2 (MILLER PD, 1985).

Apesar de essa ser a classificação mais usada dentre os periodontistas nas últimas décadas, outras também podem ser adotadas e são preconizadas por diversos autores (KAHN S, RODRIGUES VJPR e BARCELEIRO M, 2013; MYTHRI S, et al., 2015; CALDATO K, et al., 2018). 
Tem sido verificado que pacientes com fenótipo periodontal fino e que possuem estrutura óssea horizontal menor que $2 \mathrm{~mm}$ são propensos a desenvolver RG por forças ortodônticas (CORTELLINI P e BISSADA N, 2018; EDYTA K, et al., 2019). Jepsen S, et al. (2017), em seu estudo, evidenciaram, através de modelos experimentais em animais, que determinados métodos ortodônticos afetam o periodonto, resultando em reabsorção óssea alveolar, distúrbios pulpares e retrações gengivais. Porém, existem evidências de estudos observacionais que com bom controle da placa, dentes com periodonto reduzido, porém saudável, podem sofrer movimento dentário bem sucedido sem comprometer o suporte periodontal.

De fato, a literatura parece corroborar que o trauma de oclusão não é fator de destruição periodontal primária, embora seja considerado cofator na presença de doenças periodontais ativas (POONAM K, et al., 2019). Apesar de não haver um consenso estabelecido sobre este assunto, sabe-se que o movimento ortodôntico que leva a vestibularização das coroas dentárias pode ocasionar, por óbvia natureza, deiscência óssea e comprometimento da estrutura óssea vestibular. Sem o suporte ósseo adequado, a margem gengival irá, por conseguinte, retrair, expondo raízes dentárias (WANG G, et al., 2019).

No presente estudo, duas pacientes compareceram ao complexo odontológico São João do Calábria com queixa de RG classe II (MILLER PD, 1985) após conclusão de tratamento ortodôntico. Conforme preconizado na literatura científica, a técnica de deslize lateral de tecido gengival e retalho de dupla papila poderiam ser úteis, uma vez que estas possuem indicações o recobrimento radicular de RG classe I ou II (ALGHAMDI H, et al., 2009; JENABIAN N, et al., 2016). Entretanto, verifica-se que nestes casos em particular, não havia tecido queratinizado doador nas proximidades da $R G$, contraindicando qualquer técnica envolvendo retalhos pediculados. Logo, as técnicas de enxerto autógeno envolvendo a obtenção de tecido à distância foram devidamente indicadas.

De acordo com a literatura prévia, a técnica de EGL está indicada para ganho de tecido queratinizado, embora não possa garantir estética satisfatória, uma vez que o recobrimento completo, por vezes, pode não ser conseguido e que resulta em divergência de coloração do tecido doado comparado ao leito receptor. Enquanto isso, a técnica de ESTC, considerada por muitos autores como padrão ouro, pode propiciar algum ganho de tecido queratinizado e apresenta qualidade estética superior quando comparada ao EGL (RODRIGUES DC, et al., 2010; VENTURIM R, et al., 2011).

Assim, os resultados clínicos obtidos aos 45 dias de realização do procedimento cirúrgico de recobrimento radicular, no presente estudo, estão de acordo com a literatura científica. Além disso, conforme previsto para a paciente referente ao caso clínico 1 , a qual foi submetida ao EGL, será ainda realizada uma segunda abordagem cirúrgica, com deslize coronal de retalho seguida de peeling gengival ou ESTC, conforme também preconizado anteriormente (FELTRIN V, 1999).

É importante salientar que as indicações de recobrimento radicular, seja para reconstituir padrões funcionais ou estéticos do periodonto de proteção, dependem de cada caso clínico, de forma que a escolha pelo EGL ou ESTC não é algo rígido. É certo que o ESTC tem sido mais frequentemente indicado pela sua possibilidade de recuperar estética e, em alguns casos, até mesmo tecido queratinizado, sendo considerado, conforme dito anteriormente, padrão ouro em recobrimento radicular.

Entretanto, em determinadas situações específicas, quando o ganho de tecido queratinizado for necessidade superior, deve-se refletir nas indicações do EGL, uma vez que o paciente pode, ao final de uma segunda abordagem cirúrgica, obter os padrões funcionais e estéticos gengivais adequados (RIBAS AR, et al., 2016). Ambas as técnicas de EGL e ESTC possuem ótimos resultados quando bem indicadas, uma vez que apresentam vantagens e desvantagens diferenciadas quanto aos aspectos funcionais e estéticos do periodonto.

\section{REFERÊNCIAS}

1. ALGHAMDI H, et al. Surgical management of gingival recession: a clinical update. The Saudi Dental Journal, 2009; 21(2): 83-94. 
2. CALDATO $\mathrm{K}$, et al. Evaluation of periodontal bioassay in areas affected by gingival recession in dental academics. Brazilian Journal of Periodontology, 2018; 20(3): 70-81.

3. CORTELLINI P, BISSADA N. Mucogingival conditions in the natural dentition: Narrative review, case definitions, and diagnostic considerations. Journal of Clinical Periodontology, 2018; 45(20): 190-198.

4. EDYTA K, et al. Relationship between periodontal status of mandibular incisors and selected cephalometric parametres. Journal of Orofacial Orthopedics, 2019; 80(3): 107-115.

5. FELTRIN V. Periodontal estética recessão gengival. Monografia. Universidade Federal de Santa Catarina, Florianópolis, 1999; 40 p.

6. GANJI KK, et al. Facial profile based evaluation of gingival zenith position in maxillary central incisors among Saudi, Indian \& Bangladeshi population. The Saudi Dental Journal, 2018; 30(4): 342-347.

7. GUTTIGANUR N, et al. Classification systems for gingival recession and its management of a new classification system. Indian Dental of Journal Research, 2018; 29(2): 233-237.

8. HYTHAM N, et al. The accuracy and reliability of digital measurements of gingival recession versus conventional methods. BMC Oral Health, 2019; 19(2): 154-155.

9. JATI AS, et al. Gingival recession: its causes and types, the importance of orthodontic treatment. Ortodontic Insight, 2016; 21(3): 18-29.

10. JENABIAN N, et al. Gingival unit graft verses free gingival graft for treatment of gingival recession: randomized controlled clinical trial. Journal of Dentistry, 2016; 13(3): 184-192.

11. JEPSEN S, et al. Periodontal manifestations of systemic diseases and developmental and acquired conditions: Consensus report of workgroup 3 of the 2017 World Workshop on the Classification of Periodontal and Peri-Implant Diseases and Conditions. Journal of Clinical Periodontology, 2017; 45(20): 219-229.

12. JHA N, et al. Treatment of oral hyperpigmentation and gingival smile using laser and the role of plasma as a new treatment technique in dentistry. Oncotarget, 2017; 27(2): 232-238.

13. KAHN S, et al. O. Micro periodontal plastic surgery in the treatment of deep gingival recession after orthodontic movement. Case Reports in Dentistry, 2013; 18(2): 215-222.

14. KANUT A, et al. Root coverage using a connective tissue graft with epithelial striation in combination with enamel matrix derivatives - a long-term retrospective clinical interventional study. BMC Oral Health, 2019; $19(2): 148$ - 150.

15. KOLTE PA, et al. Proximal contact areas of maxillary anterior teeth and their influence on interdental papila. The Saudi Dental Journal, 2018; 30(4): 324-329.

16. LOBO M, et al. A interação da periodontia com os procedimentos estéticos. In: Estética do sorriso em reabilitação protética. 3a ed. São Paulo: Livro CIOBA; 2014;333p.

17. LUTHRA S, et al. Determination of the regenerative potential of the grafts (gold standard). Achieve $100 \%$ root coverage in the recession of Miller class III with periostal pedicle graft and autogenous bone. Indian Journal of Dentistry Research, 2018; 22(3): 277-281.

18. MILLER PD Jr. A classification of marginal tissue recession. The International Journal of Periodontics \& Restorative Dentistry.1985; 5(2):8-13.

19. MYTHRI S, et al. Etiology and occurrence of gingival recession - An epidemiological study. Journal of Indian Society of Periodontology, 2015; 19(6): 671-675.

20. PATIL V, DESAI M. Evaluation of gingival contours for aesthetic diagnosis and treatment: a clinical study. Indian Journal of Dentistry Research, 2013; 24(3): 394-395.

21. PAWAR B, et al. Gingival Zenith and its role in defining aesthetics: a clinical study. Rev. Journal of Indian Society of Periodontology, 2011; 15(2): 135-138.

22. POONAM K, et al. Elevated levels of interleukin (IL) - $1 \beta$, IL -6, tumor necrosis fator- $\alpha$, epidermal growth fator, and $\beta 2-$ microglobuin levels in gingival crevicular fluid during human Orthodontic tooth movement (OTM). Journal Family Medicine and Primary Care, 2019; 8(5): 1602 - 1606.

23. RIBAS AR, et al. Enxerto gengival livre versus enxerto de tecido conjuntivo livre - relato de caso clínico. Revista Periodontia, 2016; 26(4): 64-70.

24. RODRIGUES DC, et al. Use of the subepithelial connective tissue graft in the root covering. Revista Gaúcha de Odontologia (Online), 2010; 58(1): 115-118.

25. SEGUNDO TK, ALVES R. Use of the conjunctive epithelial gingival graft on the root covering. Indian Journal of Dentistry Research, 2005; 14(3): 380-384.

26. STEFFENS J, MARCANTONIO R. Classificação das doenças e Condições Periodontais Peri-implantares 2018: guia Prático e Pontos-Chave. Revista de Odontologia da UNESP, 2018; 47(4): 189-197.

27. VENTURIM R, et al. Surgical technique of connective tissue graft for the treatment of gingival recession. Indian Journal of Dentistry Research, 2011; 18(2): 250-253.

28. WANG G, et al. Effect of orthodontic tooth movement on keratinized gingival width. Beijing Da Xue Xue Bao Yi Xue Ban, 2019; 51(5): 931-936. 